\title{
Estimating the long-term effects of in vitro fertilization in Greece: an analysis based on a lifetime-investment model
}

This article was published in the following Dove Press journal:

ClinicoEconomics and Outcomes Research

19 June 2013

Number of times this article has been viewed

\author{
Vassilis Fragoulakis \\ Nikolaos Maniadakis \\ National School of Public Health, \\ Department of Health Services \\ Management, Athens, Greece
}

Objective: To quantify the economic effects of a child conceived by in vitro fertilization (IVF) in terms of net tax revenue from the state's perspective in Greece.

Methods: Based on previous international experience, a mathematical model was developed to assess the lifetime productivity of a single individual and his/her lifetime transactions with governmental agencies. The model distinguished among three periods in the economic life cycle of an individual: (1) early life, when the government primarily contributes resources through child tax credits, health care, and educational expenses; (2) employment, when individuals begin returning resources through taxes; and (3) retirement, when the government expends additional resources on pensions and health care. The cost of a live birth with IVF was based on the modification of a previously published model developed by the authors. All outcomes were discounted at a $3 \%$ discount rate. The data inputs - namely, the economic or demographic variables - were derived from the National Statistical Secretariat of Greece and other relevant sources. To deal with uncertainty, bias-corrected uncertainty intervals (UIs) were calculated based on 5000 Monte Carlo simulations. In addition, to examine the robustness of our results, other one-way sensitivity analyses were also employed.

Results: The cost of IVF per birth was estimated at $€ 17,015$ (95\% UI: $€ 13,932-€ 20,200)$. The average projected income generated by an individual throughout his/her productive life was $€ 258,070$ (95\% UI: $€ 185,376-€ 339,831)$. In addition, his/her life tax contribution was estimated at $€ 133,947$ (95\% UI: $€ 100,126-€ 177,375)$, while the discounted governmental expenses for elderly and underage individuals were $€ 67,624$ (95\% UI: $€ 55,211-€ 83,930)$. Hence, the net present value of IVF was $€ 60,435$ (95\% UI: $€ 33,651-€ 94,330$ ), representing a $182 \%$ net return on investment. Results remained constant under various assumptions for the main model parameters.

Conclusion: State-funded IVF may represent good value for money in the Greek setting, since it has positive tax benefits for the government, notwithstanding its beneficial psychological effect on infertile couples.

Keywords: cost-benefit analysis, net tax revenue, lifetime productivity, infertility

\section{Introduction}

Infertility is a condition which, while not a direct threat to physical health, is associated with psychological distress and impaired well-being, and may even lead to divorce or social stigmatization. ${ }^{1}$ Although there is not yet a universally accepted definition of "infertility," and the general public has incomplete comprehension of reproductive science terminology, ${ }^{3}$ a simple medical definition of it could be "failure to conceive following twelve months of unprotected intercourse." Global estimates of infertility in couples with women of childbearing age range between $8 \%$ and $12 \%$, meaning that it affects between 50 and 80 million people. ${ }^{5}$ It has been estimated that the incidence of
Correspondence: Vassilis Fragoulakis Department of Health Services and Management, National School of Public Health, Alexandras Av 196, Athens II52I, Greece

Tel +302132010207

$\mathrm{Fax}+302132010194$

Emailvfragoulakis@yahoo.com 
infertility is associated with geographic differences between developed and developing countries. ${ }^{6-8}$ The American Urologic Association and European Association of Urology claim that the male factor is solely responsible in $20 \%$ of cases and contributory in an additional $30 \%$ of infertility cases. $^{9}$

Common risk factors for infertility in both sexes include age, tobacco smoking, alcohol use, excess weight, caffeine intake, occupational and environmental risks, emotional factors, and chronic illnesses such as diabetes or thyroid disease. ${ }^{10}$ For women, sexually transmitted infections and other health problems that cause hormonal changes such as polycystic ovarian syndrome and primary ovarian insufficiency - could increase the risk of infertility. ${ }^{11}$

The science and methodology of in vitro fertilization (IVF) have improved considerably in the last 25 years, offering the obvious benefit of boosting the odds of getting pregnant, sometimes from almost zero. Nowadays, IVF treatment is applied using new techniques and strategies that aim to optimize success rates and avoid any safety risks for women. ${ }^{12}$ Originally, IVF was indicated for women with tubal-factor infertility but now it represents a viable treatment option for many different causes of infertility when conventional therapy fails or is unlikely to be successful. ${ }^{12}$ However, in spite of its advantages, IVF remains inconvenient and may cause psychological disorders in the parents and/or the child born. ${ }^{13}$ In addition, IVF remains expensive, a fact that has led to debate over its public funding and the question of whether society should be willing to pay for live births. ${ }^{13}$

In Greece, infertility represents a multidimensional problem with potentially severe social, economic, and cultural implications, which is developing alarming proportions due to the underlying demographic trends. ${ }^{14}$ The birth rate, which reflects the average annual number of births during a year per 1000 persons in the population at midyear, has declined steadily from 9.82 to 9.08 over the last 12 years (2000-2012).$^{15}$ According to the latest available data, the average birth rate in the European Union is currently estimated to be $10.27 .{ }^{15}$ The birth rate is usually the main factor in determining the rate of population growth and depends on both the level of fertility and the age structure of the population. ${ }^{15}$ In addition, the total fertility rate was determined to be 1.39 for Greece, compared with 1.58 for the European Union in 2012. "Total fertility rate" is another measure of the level of fertility that is more direct than the crude birth rate, since it refers to births per woman. This indicator shows the potential for population change in the country. A rate of two children per woman is considered the replacement rate for a population, resulting in relative stability in terms of total numbers, while a rate below two children indicates a population that is decreasing in size and growing older. These significant population features are causing concern, especially in Greece, due to potential changes in the structure of the labor market, the national economy, and society as a whole in the near future.

\section{Methods Objective}

Greece is currently going through the most significant economic crisis in its modern history, and public health budgets are decreasing rapidly in the context of austerity measures that aim to reduce public spending. In this light, drug budgets are steadily being reduced in an effort to curtail public drug spending from $2 \%$ to $1 \%$ of gross domestic product (GDP) within a period of 4 years. Hence, this paper reports an economic evaluation undertaken to assess the long-term economic effects for the public state budget from the adoption of a publicly funded IVF treatment program in Greece. In particular, the scope of this research was to quantify the long-term and the net economic effects of achieving a live birth with IVF, in terms of net tax revenue from the perspective of the Greek state.

\section{Description of the model}

Based on previous international data and experience, ${ }^{16-18}$ a probabilistic mathematical model was developed to assess the lifetime productivity of a single individual and his/her lifetime transactions with the various governmental agencies. This model was based on cost-benefit analysis principles designed to determine whether a given item of health care expenditure is socially worthwhile. The methodology that was used is referred to as "generational accounting" (GA). This type of methodology was developed to evaluate whether current governmental fiscal policies will disproportionately burden future generations. ${ }^{16} \mathrm{GA}$ is used to evaluate the present value of lifetime net taxes - gross taxes minus direct financial transfer (health, education, pension, etc) - for population cohorts over many generations. ${ }^{16}$ In principle, GA considers whether there will be sufficient tax revenue collected in the future to pay for government programs, whether tax increases or other policy adjustments are necessary to cover government expenditures in the future, and whether the tax burden is evenly distributed over generations or if costs will simply be passed on to future generations. ${ }^{16}$

Thus, the model presented here distinguishes and computes analyses for three periods in the life cycle of an 
individual: (1) early life, when the government primarily contributes resources, indirectly and directly, through child tax credits and educational expenses; (2) employment, when individuals begin returning resources to the state through taxes; and (3) retirement, when the government expends additional resources on pensions. The full structure of the model used is presented in Table 1.

\section{Quantification of the model}

Following the concept of previous models of this type, we derived the net tax contribution $(€)$ as follows:

$$
\mathrm{NTC}=-\mathrm{CLB}-\mathrm{CTC}-\mathrm{H}-\mathrm{E}+\mathrm{IT}+\mathrm{VAT}-\mathrm{P},
$$

where NTC stands for net tax contribution, CLB for cost of live birth, CTC for child tax credits, $\mathrm{H}$ for health care cost, $\mathrm{E}$ for education cost, IT for income taxes, VAT for valueadded tax, and $\mathrm{P}$ for pension.

To express the present value of investing in IVF, all outcomes were discounted at a $3 \%$ discount rate, but other options were also employed in a one-way sensitivity analysis. The model assumed that in 2012 the life expectancy at birth was 80 years of age and the annual per capita GDP (market prices) was estimated at $€ 19,018$, based on official data. ${ }^{19}$

\section{Cost of live birth}

The cost of a live birth with IVF was based on a modification of a previously published model that was developed and locally adapted by the authors; a detailed description of this model can be found elsewhere. ${ }^{20}$ In brief, a modeling approach was utilized to reflect the main different pathways in the management of patients treated with IVF in Greece. Specifically, a decision tree in combination with a Markov model was adapted ${ }^{21}$ and customized to assess the clinical and economical outcomes of the main conventional treatments used in the country. The model simulated the progression of patients from the moment they start therapy to various different states during treatment cycles. The first cycle was a complete treatment cycle with the aim of obtaining egg cells, fertilizing them, and performing embryo transfer. This process may result in an actual pregnancy and birth, or may fail; in the latter case there could be a new complete treatment cycle, a frozen embryo transfer if cryopreservation of embryos is available, or an individual may decide to stop the IVF effort. Given the IVF protocols applied in Greece, the time horizon of the model was set up to include three consecutive IVF cycles. Based on this model, the mean cost per live birth was estimated at $€ 17,096( \pm € 570)$.

\section{Child tax credits}

It must be noted that the tax system in this country is quite complex. In addition, despite the fact that the consequences of the financial crisis can be devastating for Greek children, maternity and the prevention of child poverty do not appear to be a policy priority area in Greece. ${ }^{22}$ For our purposes, the child tax credits in the model were based on data provided by the Organisation for Economic Co-operation and Development's "Family database calculator," ${ }^{23}$ which represents the newest update of the Organisation for Economic Co-operation and Development's tax-benefit policy indicators across many European countries. This calculator is an official Microsoft Excel $^{\circledR}$-based tool that allows researchers to determine the tax and social benefits of maternity in several countries, taking into account birth-related payments, financial assistance, and in-work benefits. In practice, the amount of child tax credits is different for every family, based on its economic characteristics (number of children, income, etc).

Our model assumed that the gross earnings of the first adult equaled $100 \%$ of the average European wage, the gross earnings of the second adult were $50 \%$ of the European average, and that the IVF singleton was the only child in the family. Thus, sole-parent families, unemployed adults, and families with two or more children were not taken into account in the base-case analysis. Under these assumptions, for the year of birth, the benefit was estimated at $€ 980$ in terms of wages, while maternity and paternity leave payments were estimated at $€ 6582$ and $€ 2361$, respectively. For each subsequent year until the age of 20 , the tax credit was determined at $€ 99$ per year.

Table I Structure of the model

\begin{tabular}{|c|c|c|c|}
\hline Baby born by IVF (-) & $\begin{array}{l}\text { Early life }(-) \\
(0-21 \text { years of age })\end{array}$ & $\begin{array}{l}\text { Employment }(+) \\
(22-65 \text { years of age) }\end{array}$ & $\begin{array}{l}\text { Retirement }(-) \\
(66-81 \text { years of age) }\end{array}$ \\
\hline $\begin{array}{l}\text { - Cost of IVF (funded by } \\
\text { the state) (-) }\end{array}$ & $\begin{array}{l}\text { - Child tax credits }(-) \\
\text { - Education }(-) \\
\text { - Health care }(-)\end{array}$ & $\begin{array}{l}\text { - Income taxes }(+) \\
\text { - Value-added tax }(+) \\
\text { - Health care }(-)\end{array}$ & $\begin{array}{l}\text { - Pensions }(-) \\
\text { - Health care }(-)\end{array}$ \\
\hline
\end{tabular}

Note: (-) financially "negative" from a state perspective; (+) financially "positive" from a state perspective. Abbreviation: IVF, in vitro fertilization. 


\section{Health care cost and pensions}

Health care cost is one of the most difficult parameters to estimate or predict. According to official Eurostat data, government expenditure on health care in Greece in 2012 was $7.5 \%$ of the GDP. ${ }^{24}$ To reflect differences in health care consumption during life, we used age-specific estimates taken from the relevant literature. ${ }^{25}$ It is generally known that the distribution of health care costs is strongly age dependent. Health care costs are lowest for children, rise slowly throughout adult life, and increase significantly after the age of 50 years. ${ }^{25}$ According to the literature, ${ }^{25}$ the life of an individual can be divided into five distinct periods, namely: "childhood" (0-19 years), "young adult" (20-39 years), "middle-aged adult" (40-64 years), "senior years" (65-84 years), and "old senior years" ( $85+$ years). The consumption of health care costs in comparison with the national average was estimated to be $49.1 \%, 20.8 \%$, $37.3 \%, 147.2 \%$, and $245.2 \%$, respectively, for these periods. In our model, we used only the first four categories, since the model is a cohort model that stops at the time horizon of 81 years (Figure 1). To deal with uncertainty in these rates, we conducted a probabilistic sensitivity analysis.

It must be stressed that it is extremely difficult to predict state pension reforms in the future with any degree of certainty. Thus, it was assumed that the average pension in the country was $€ 700$ per month for those belonging to the age group of $65+$ within the time horizon of the model. Hence, the age of retirement was assumed to be 65 years of age.

\section{Education}

The total general government expenditure on education in Greece was estimated at $€ 8,577$ million, or $€ 722.68$ per personyear, representing $3.8 \%$ of the GDP. ${ }^{26}$ In addition, according to the latest available data for 2005 concerning the expenditure

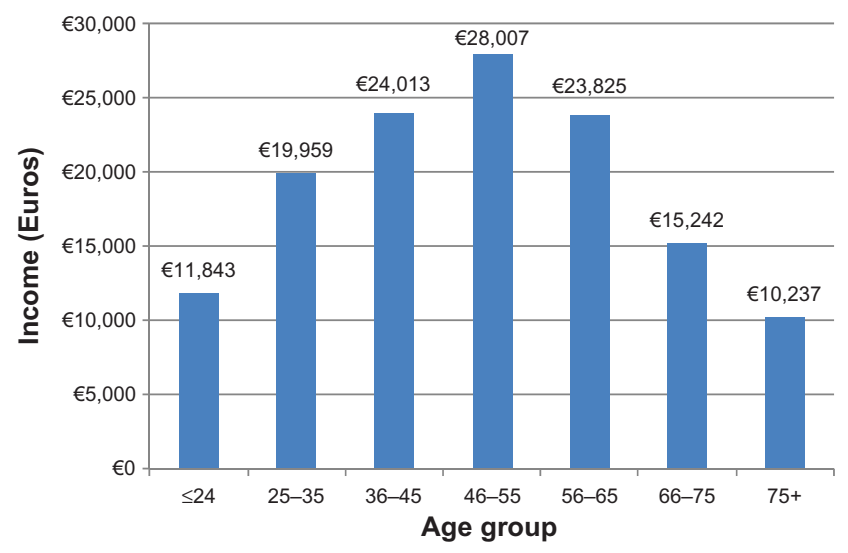

Figure I Average estimated income by age group. per educational level, it was estimated that the annual costs among primary and secondary/post-secondary education differ by $28 \%$, on average. As such, the modeled cost of education per person was estimated for these two categories separately, at $€ 619.61$ and $€ 825.54$, respectively. It was further assumed that each person stays out of the labor force until the age of 21, on average, to undertake post-secondary education.

\section{Income taxes and value-added tax}

According to provisional data provided by Eurostat, the implicit tax rate (ITR) on personal income is $31 \%$, while the ITR on consumption was estimated to be $15.8 \%$ in the case of Greece in 2012. ${ }^{26}$ ITR measures the average tax burden on different types of economic income or activities, such as labor and consumption (capital was excluded from our analysis). ITR expresses aggregate tax revenue as a percentage of the potential tax base for each field. The ITR on labor is the ratio between taxes and social contributions paid on earned income and the cost of labor. ${ }^{27}$ The numerator includes all direct and indirect taxes and social contributions levied on employed labor income, while the denominator amounts to the total compensation of employees working in the economic territory, increased by taxes on wage bills and the payroll. It is calculated for employed labor only (excluding the tax burden falling on social transfers, including pensions). The ITR on consumption is the ratio between the revenue from consumption taxes and the final consumption expenditure of households in the economic territory. ${ }^{27}$ Hence, the economic benefit for government was estimated by multiplying the GDP/capita by $(31.0 \%+15.8 \%)$. To take into account the age-dependent nature of income and, consequently, the tax contribution, average age-stratified income per age group was obtained from the last "Household budget survey," 19 which was conducted in a representative sample of households throughout the country. For our purposes, and given the lack of detailed data, it was assumed that the available monthly expenditure for services and goods is a crude but reasonable proxy of the available income by age group. ${ }^{19}$ The data analysis showed that people in the 46-55 year age group had the highest available income in comparison with the other age groups. It must be mentioned that the GDP/capita ratio took into account the unemployment rate, which was therefore not included further in the analysis. Due to the lack of detailed data, property tax was not included in the present model.

\section{Dealing with uncertainty}

It is generally known that data used in economic analyses such as this one are truncated at zero and do not follow normal 
distributions; consequently, construction of $95 \%$ confidence intervals would be invalid if conducted using conventional approaches (ie, based on the central limit theorem). As such, in the present model, bias-corrected uncertainty intervals (UIs) were calculated using the percentile method of nonparametric simulation (Table 2). ${ }^{28}$ Probability distributions were therefore specified around the main model parameters. In particular, all cost components were associated with a gamma distribution and $10 \%$ of the coefficient of variation around the mean was used for probabilistic sensitivity analysis (1000 bootstrap replications). In addition, a supplementary one-way sensitivity analysis was conducted. Hence, all the main parameters of the model were varied over $\pm 10 \%$ to examine the stability and the robustness of results under different assumptions.

\section{Results}

Figures 2, 3 and Table 3 present the main results of the analysis. All statistical calculations were performed using Microsoft (Redmond, WA, USA) Excel ${ }^{\circledR} 2003$. Probabilistic sensitivity analysis revealed that there was a statistically significant difference between the taxes that an individual will contribute to the state throughout his/her productive life and the lifelong governmental expenses for an individual. The average projected cumulative income generated by an individual was estimated at $€ 838,139$ (95\% UI: $€ 675,957-€ 1,006,035)$ with no discounting, and at €258,070 (95\% UI: €185,376-€339,831) when a discount rate was used. The income taxes plus valueadded tax contribution for an average individual was estimated at $€ 133,947$ (95\% UI: $€ 100,126-€ 177,375$ ) with no discounting, and at $€ 462,776$ (95\% UI: $€ 388,073-€ 555,853$ ) in the case of discounting. In contrast, the governmental

Table 2 Main parameters used in the model

\begin{tabular}{lll}
\hline Description & Value & $\begin{array}{l}\text { Distribution used } \\
\text { for PSA** }\end{array}$ \\
\hline Life expectancy at birth & 81 years & - \\
Discount rate & $3.00 \%$ & Beta \\
GDP per capita (market price) & $€ 19,018$ & Gamma \\
Cost of IVF & $€ 17,096$ & Gamma \\
$\begin{array}{l}\text { Education (primary, secondary } \\
\text { or upper) }\end{array}$ & $€ 619 / € 825$ & Gamma \\
$\begin{array}{l}\text { Income tax* } \\
\text { Value-added tax* }\end{array}$ & $31.00 \%$ & Beta \\
Health care and social security & $15.10 \%$ & Beta \\
costs* & $7.5 \%$ & Beta \\
Pension per month & $€ 700$ & Gamma \\
\hline
\end{tabular}

Notes: *As \% of GDP; **probabilistic sensitivity analysis (PSA) with a $10 \%$ coefficient of variation.

Abbreviation: GDP, gross domestic product; IVF, in vitro fertilization.

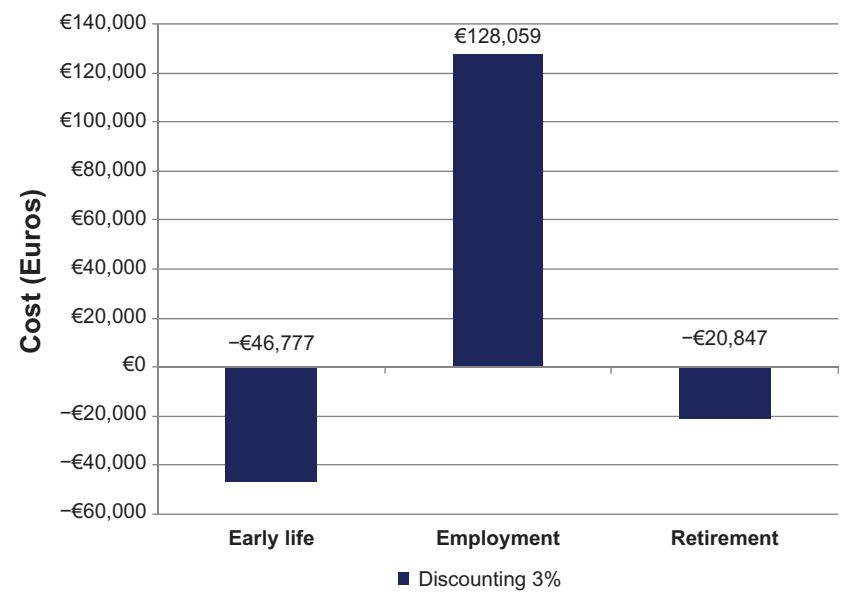

Figure 2 The economic life cycle of an individual. Note: A discount rate of $3 \%$ was used for future costs.

expenses for elderly individuals (with discounting) were estimated at $€ 20,847$ (95\% UI: $€ 12,755-€ 32,439$ ), while the expenses for underage individuals were $€ 46,777$ (95\% UI: $€ 42,456-€ 51,491)$. In accordance with the aforementioned analysis, IVF represents an attractive economic option, with a $182 \%$ net return on investment.

Table 4 represents the results of the one-way sensitivity analysis. In general, the most sensitive parameters concerning the net benefit of IVF were the discount rate, the value-added tax rate, and the tax rate. Other parameters, such as the child tax credits, the cost of education, or even the cost of IVF, had less impact on the results. In addition, we conducted a supplementary one-way analysis called "break-even point" (BEP) analysis. BEP estimates the value of a certain parameter of the model for which the governmental expenses and the financial contribution of an individual become equal (namely, when the net present value of IVF

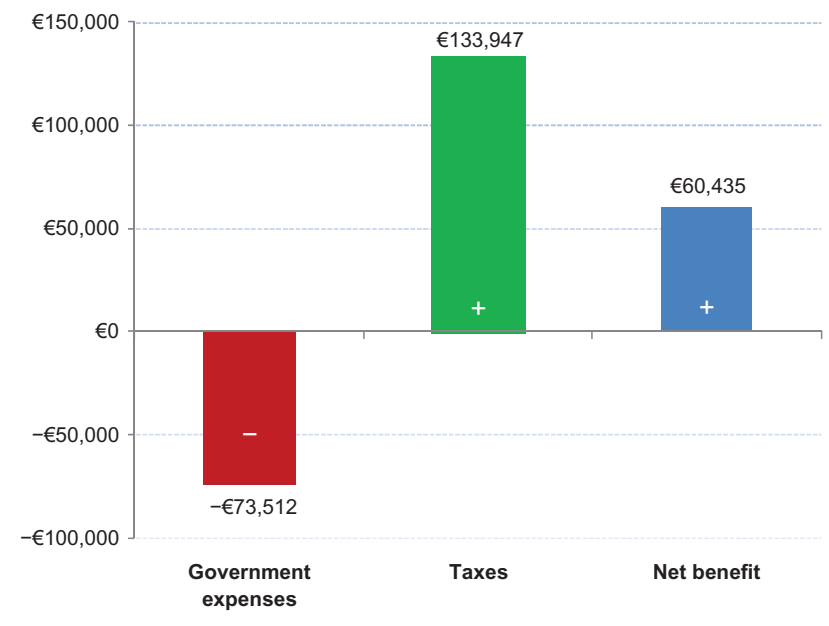

Figure 3 The net present value of in vitro fertilization per capita. 
Table 3 Main results of the model

\begin{tabular}{|c|c|c|c|}
\hline & Mean & LUI & UUI \\
\hline \multicolumn{4}{|l|}{ Discount rate $3 \%$} \\
\hline Cost of IVF & $-€ \mid 7,028$ & $-€ 20,200$ & $-€ \mid 3,932$ \\
\hline Education & $-€ 7373$ & $-€ 8566$ & $-€ 6260$ \\
\hline Child tax credits & $-€ I I, 342$ & $-€ \mid 3,273$ & $-€ 9474$ \\
\hline Health care cost & $-€ 20,664$ & $-€ 26,380$ & $-€|5,5| 6$ \\
\hline Pensions & $-€ \mid 7,105$ & $-€ 25,870$ & $-€ 10,137$ \\
\hline Income tax + value-added tax & $€ 133,947$ & $€ 100,126$ & $€ I 77,375$ \\
\hline Net present value of IVF & $€ 60,435$ & $€ 33,65 I$ & $€ 94,330$ \\
\hline \multicolumn{4}{|l|}{ No discounting } \\
\hline Cost of IVF & $€-17,028$ & $-€ 20,200$ & $-€ 13,932$ \\
\hline Education & $-€ 10,894$ & $-€ 12,490$ & $-€ 9427$ \\
\hline Child tax credits & $-€ 11,959$ & $-€ \mid 3,920$ & $-€ 10,116$ \\
\hline Health care cost & $-€ 69,045$ & $-€ 82,784$ & $-€ 55,636$ \\
\hline Pensions & $-€ \mid 42,694$ & $-€|70,03|$ & $-€ \mid I 5,532$ \\
\hline Income tax + value-added tax & $€ 462,776$ & $€ 388,073$ & $€ 555,853$ \\
\hline Net present value of IVF & $€ 211,156$ & $€ 132,674$ & $€ 308,539$ \\
\hline
\end{tabular}

Note: Analysis was based on 1000 bootstrap replications.

Abbreviations: IVF, in vitro fertilization; LUI, lower uncertainty interval; UUl, upper uncertainty interval.

is equal to zero). According to the results, the BEP for the cost of IVF was estimated to be as high as $€ 83,419$, with the discount rate estimated at $6.05 \%$, the IT rate at $8.39 \%$, and the monthly pension at $€ 3484$. Hence, it seems that, from the economic point of view, IVF may represent an attractive option for public funding.

\section{Discussion}

Understanding the relative benefits and costs of IVF for infertile couples and the state is crucial to ensure that patients receive effective and efficient therapy from the limited health care resources available. Nowadays, there is controversy concerning the appropriate level and source of funds for assisted reproduction technologies, in particular IVF, in most developed economies. ${ }^{29}$ It is frequently characterized by low public (or other third party) funding and a greater

Table 4 One-way sensitivity analysis for the main model parameters*

\begin{tabular}{lll}
\hline Parameters & \multicolumn{2}{l}{ Net benefit $(€)$} \\
\cline { 2 - 3 } & $-10 \%$ & $+10 \%$ \\
\hline Discount rate $(2.7 \%, 3.3 \%)$ & $€ 72,435$ & $€ 52,535$ \\
Cost of IVF $(€|5,386, €| 8,806)$ & $€ 63,603$ & $€ 60,183$ \\
Income tax** $(27.9 \%, 34.1 \%)$ & $€ 52,799$ & $€ 70,987$ \\
Value-added tax** $(13.59 \%, 16.61 \%)$ & $€ 57,463$ & $€ 66,323$ \\
Health care cost $(6.75 \%, 8.25 \%)$ & $€ 63,927$ & $€ 59,859$ \\
\hline
\end{tabular}

Notes: *The analysis was based on deterministic results and is slightly different from bootstrap experiments due to the correction bias term. In particular, the deterministic net benefit without correction bias was estimated at $€ 61,893$ against $€ 60,435$ in the bootstrap experiments; **As \% of GDP.

Abbreviations: GDP, gross domestic product; IVF, in vitro fertilization. reliance on user pays, depending on the health care system. In Greece, in the current context of politico-economic crisis, the country's coalition government recently agreed to a reform program with the International Monetary Fund, aiming to reduce the total public health care expenditure. ${ }^{30}$ In such a situation, and for a temporary period, the amount of money that the government is willing to spend for an IVF-conceived child (live birth) could be potentially lower than the formal threshold proposed by the World Health Organization. ${ }^{31}$ Nonetheless, the analysis undertaken in the present study showed that funding of the IVF process represents a good use of public resources with economic rewards (positive net economic benefit) for Greece. In addition, probabilistic analysis showed that the results remained constant at the $95 \%$ level of significance. It must be noted that this type of economic evaluation, which compares the net benefit of different health policies with a long-term horizon, has limited reports in the literature and the conclusions are relatively inconsistent. Thus, further investigation of the economic implications of infertility treatments by qualified researchers is needed. ${ }^{32}$ To the best of our knowledge, this is the first economic study conducted on Greece.

In a model applied to the UK, ${ }^{16}$ there was an attempt to develop a health investment model to evaluate whether a state-funded IVF program represents a sound fiscal policy. The analysis revealed that the economic investment to achieve an IVF live birth is actually worth 8.5 -times this amount to the UK Treasury in discounted future tax revenue. ${ }^{16}$ Another model attempted to evaluate whether lifetime future net tax revenue from an IVF-conceived child is sufficiently substantial to warrant public subsidy, relative to the mean IVF treatment costs required to obtain one live birth. ${ }^{17}$ This model estimated the total IVF cost to the government required to conceive a child. Then the model estimated the future net tax revenue to government, offset by direct financial transfers from the government (child allowances, education, Medicare, and Social Security). According to the results, the child's initial IVF investment represented a $700 \%$ net return in discounted US dollars. In another modified GA model, which was developed for Sweden, ${ }^{33}$ it was revealed that state-funded IVF does not negatively impact the long-run fiscal budget; conversely, over an average lifetime, an IVF offspring returns a positive net value to the state. Another model, developed for Brazil, estimated that the fiscal contribution generated by each IVF-conceived citizen can justify an initial government investment in infertility treatment, but this initial expenditure may be compensated for by the fiscal contribution in the next generation. ${ }^{34}$ Similarly, 
an analysis conducted for the Danish government concluded that IVF funding cuts would negatively impact the future government inflows due to lost tax revenue. ${ }^{18}$

Nonetheless, certain concerns have been raised about the future sustainability of health care systems from a statefunded IVF policy. For instance, IVF has vastly increased the numbers of multiple births - which carry major risks including premature birth, low birth weight, preeclampsia, and placenta previa - and consequently places a strain on the health care system and the economy. ${ }^{35}$ Further, children born from IVF therapies seem to have a statistically elevated risk of cancer, ${ }^{36}$ while mothers who commence IVF treatment at a young age are subject to an increased rate of breast cancer. $^{37}$

Based on the above considerations, it must be clear that modeling is a simplification of the process it tries to emulate, and it was necessary to make strong assumptions when constructing our model. The analysis described herein was based on a simulation and on synthesized data, and not on local data from databases or Greek registries. In practice, the management of patients with infertility is extremely complex in every health care setting. In addition, the courses of the patients' and their children's lives, their future contribution to the economy, their health care expenses, and so forth, are subject to great uncertainty and cannot be accurately modeled easily. For instance, according to a recent systematic review of the literature, the long-term effectiveness of IVF is unclear, while the most important predictive factor for a positive outcome (live birth) is not the drug used or its cost, but the age of the woman. ${ }^{38}$

Moreover, in the context discussed here, only the perspective of the state has been taken into account. Hence, a profound limitation of the analysis is that it does not consider the broader contribution of the individual to the country's economic growth and the future increased demand for goods and services. Neither does the analysis take into account the fact that IVF may be used as a valuable means to mitigate the consequences of very low fertility, which represents a major demographic problem in Greece. Further, the increased morbidity that may be applicable to some IVFconceived children, the cost of twins or even triplets, and the potential economic impact of the long-term side effects of IVF on mothers were not taken into account in our model. IVF children are often preterm or have low birth weight, and may have a higher risk for certain disorders, such as cerebral palsy; in this study, we focused primarily on economics, so our analysis did not take into account the effects of this type of economic burden for society.
To deal with the aforementioned uncertainties and to develop a reliable, effective, and evidence-based policy for Greece, it is paramount to conduct a pragmatic and systematic long-term assessment of women's and children's health after IVF, especially after prolonged treatment with IVF. ${ }^{38}$

Finally, the model is characterized by an inevitable longterm uncertainty that is associated with important macroeconomic and demographic variables, such as the available income per capita, the discount rate, governmental expenses for health care, education, and labor productivity.

In a similar model to the one discussed here, labor productivity growth estimates might be incorporated to reflect the changes in productivity (and consequently wages and transfers) over the years. For instance, in the case of the UK, a $1.9 \%$ productivity growth estimate was determined for a similar model by Connolly et al. ${ }^{16}$ Nonetheless, it must be highlighted that labor productivity is calculated by dividing the real output of the economy by the total working hours of employment. Due to its nature as a ratio, its value can increase not just if the numerator increases, but also if the denominator decreases, thus implying a higher unemployment rate. In addition, today's financial and economic issues in Greece add a high degree of unpredictability to the future of the economy, and make it much more difficult to predict either the real output or the unemployment rate in Greece with any degree of certainty. Hence, a zero-productivity growth scenario was assumed for the present model throughout its whole scope until the time horizon.

It must be also noted that the GDP per capita is not always an ideal approach for evaluating income, since it might be overestimated; there are several ways to determine it in macroeconomic theory and it has been frequently used as an indicator of the level of economic activity in a country. Another alternative and better indicator to describe the welfare situation of households or individuals - in the absence of detailed data for reported earnings - is actual individual consumption per capita; however, these two indicators are fairly close to each other in the case of Greece. In addition, it must be mentioned that income levels across the lifetime of an individual reflect the different life economic stages that people have reached (low income, high income, or unemployment at any moment throughout their life). In the present model, GDP per capita was used as the sole estimator of annual income, but probabilistic sensitivity analysis was used to deal with this type of uncertainty.

The results of this model are not transferable, as is usually the case in economic evaluations, ${ }^{39}$ and have to be considered strictly in the context of the Greek setting and on the basis 
of the current management practice, health resource prices, the model's assumptions, and the health-related policies adopted in the country.

\section{Conclusion}

State-funded IVF may represent good value for money in the Greek setting, since it has positive tax benefits for the government, notwithstanding its beneficial psychological effect for infertile couples. Further long-term research, in a real-life setting, is needed to provide useful conclusions concerning the state-funded IVF policy in Greece.

\section{Acknowledgment}

The authors would like to thank Mr Philip Lees, technical editor of the Hellenic Journal of Cardiology, for his critical assistance with the English text.

\section{Disclosure}

The authors declare no conflicts of interest in this work.

\section{References}

1. Khetarpal A, Singh S. Infertility: Why can't we classify this inability as disability? Australas Med J. 2012;5(6):334-339.

2. Mascarenhas MN, Cheung H, Mathers CD, Stevens GA. Measuring infertility in populations: constructing a standard definition for use with demographic and reproductive health surveys. Popul Health Metr. 2012;10(1):17.

3. Smeyers C, Wallach H, Woodruff T. Repropedia: A reproductive lexicon to fill the gap in reproductive terminology. Biol Reprod. 2012;87(4):98.

4. de Melo-Martin I. On cloning human beings. Bioethics. 2002; 16(3):246-265.

5. World Health Organization (WHO). Gender and genetics [webpage on the Internet]. Geneva: WHO. Available from: http://www.who. int/genomics/gender/en/index6.html. Accessed at September 9, 2012 .

6. Benagiano G, Bastianelli C, Farris M. Infertility: a global perspective. Minerva Ginecol. 2006;58(6):445-457. Italian.

7. Gnoth C, Godehardt E, Frnk-Herrmann P, Friol K, Tigges J, Freundl G. Definition and prevalence of subfertility and infertility. Hum Reprod. 2005;20(5):1144-1147.

8. Boivin J, Bunting L, Collins JA, Nygren KG. International estimates of infertility prevalence and treatment-seeking: potential need and demand for infertility medical care. Hum Reprod. 2007;22(6): 1506-1512.

9. Trost LW, Nehra A. Guideline-based management of male infertility: Why do we need it? Indian J Urol. 2011;27(1):49-57.

10. http://www.mayoclinic.com. Accessed at September 25, 2012.

11. US Department of Health and Human Services Office on Women's Health. Infertility [fact sheet]. Washington DC: US Department of Health and Human Services Office on Women's Health. Available from: http://www.womenshealth.gov/publications/our-publications/ fact-sheet/infertility.pdf. Accessed September 26, 2012.

12. Goldberg JM, Falcone T, Attaran M. In vitro fertilization update. Cleve Clin J Med. 2007;74(5):329-338.

13. Griffiths A, Dyer SM, Lord SJ, Pardy C, Fraser IS, Eckermann S. A cost-effectiveness analysis of in-vitro fertilization by maternal age and number of treatment attempts. Hum Reprod. 2010;25(4): 924-931.
14. Roupa Z, Polikandrioti M, Sotiropoulou P, et al. Causes of infertility in women at reproductive age. Health Science Journal. 2009;3(2): 80-87.

15. IndexMundi. Historical data graphs per year: Greece; birth rate. Available from: http://www.indexmundi.com/g/g.aspx?v=25\&c=gr\&l=en. Accessed September 26, 2012.

16. Connolly M, Gallo F, Hoorens S, Ledger W. Assessing long-run economic benefits attributed to an IVF-conceived singleton based on projected lifetime net tax contributions in the UK. Hum Reprod. 2009;24(3):626-632.

17. Connolly MP, Pollard MS, Hoorens S, Kaplan BR, Oskowitz SP, Silber SJ. Long-term economic benefits attributed to IVF-conceived children: a lifetime tax calculation. Am J Manag Care. 2008;14(9): 598-604.

18. Connolly MP, Postma MJ, Crespi S, Andersen AN, Ziebe S. The longterm fiscal impact of funding cuts to Danish public fertility clinics. Reprod Biomed Online. 2011;23(7):830-837.

19. http://www.statistics.gr. Accessed October 5, 2012.

20. Fragoulakis V, Kourlaba G, Tarlatzis B, Mastrominas M, Maniadakis N. Economic evaluation of alternative assisted reproduction techniques in management of infertility in Greece. Clinicoecon Outcomes Res. 2012;4:185-192.

21. Schoffsci O, Sowietzki S, Ludwig M. Decision tree analysis to determine the cost-effectiveness of r-FSH compared to u-HMG in treatment cycles with assisted reproduction techniques. Pharmacoeconomics. 2007;5(1):29-39.

22. Matsaganis M. Child Poverty and Child-Well Being in the European Union: Policy Overview and Policy Impact Analysis; A Case Study: Greece. Budapest: Tárki [website on the Internet]; nd. Available from: http://www.tarki.hu/en/research/childpoverty/case_studies/ childpoverty_greece.pdf. Accessed October 4, 2012.

23. Organisation for Economic Co-operation and Development (OECD). OECD family database: the family support calculator [web-based tool]. Paris: OECD; nd. Available from: http://www.oecd.org/els/ familiesandchildren/oecdfamilydatabasethefamilysupportcalculator. htm\#features. Accessed May 22, 2013.

24. Eurostat. Total General Government Expenditure on Social Protection and Health by Country 2002 and 2010 (\% of GDP and Millions of Euro in 2010). Luxembourg: Eurostat; 2012. Available from: http://epp. eurostat.ec.europa.eu/statistics_explained/index.php?title=File:Total_ general_government_expenditure_on_social_protection_and_ health_by_country_2002_and_2010_(\%25_of_GDP_and_ millions_of_euro_in_2010).png\&filetimestamp=20120801091927. Accessed May 22, 2013.

25. Alemayehu B, Warner KE. The lifetime distribution of health care costs. Health Serv Res. 2004;39(3):627-642.

26. Eurostat. General government expenditure statistics [webpage on the Internet]. Luxembourg: Eurostat; 2012. Available at: http://epp.eurostat. ec.europa.eu/statistics_explained/index.php/General_government_ expenditure_statistics\#General_government_expenditure_by_function. Accessed October 4, 2012.

27. Eurostat. Taxation trends in the European Union: further increase in VAT rates in 2012; corporate and top personal income tax rates inch up after long decline [news release]. Luxembourg: Eurostat; May 21, 2012. Available from: http://epp.eurostat.ec.europa.eu/cache/ ITY_PUBLIC/2-21052012-BP/EN/2-21052012-BP-EN.PDF. Accessed October 4, 2012.

28. Desgagné A, Castilloux AM, Angers JF, LeLorier J. The use of the bootstrap statistical method for the pharmacoeconomic cost analysis of skewed data. Pharmacoeconomics. 1998;13(5 Pt 1):487-497.

29. Devlin N, Parkin D. Funding fertility: issues in the allocation and distribution of resources to assisted reproduction technologies. Hum Fertil (Camb). 2003;6 Suppl 1:S2-S6.

30. Fragoulakis V, Kourlaba G, Goumenos D, Konstantoulakis M, Maniadakis N. Economic evaluation of intravenous iron treatments in the management of anemia patients in Greece. ClinicoEconomics Outcomes Res. 2012;4:127-134. 
31. Zhao FL, Yue M, Yang H, Wang T, Wu JH, Li SC. Willingness to pay per quality-adjusted life year: is one threshold enough for decisionmaking?: results from a study in patients with chronic prostatitis. Med Care. 2011;49(3):267-272.

32. Jain T, Hornstein MD. To pay or not to pay. Fertil Steril. $2003 ; 80(1)$ : 27-29.

33. Svensson A, Connolly M, Gallo F, Hägglund L. Long-term fiscal implications of subsidizing in-vitro fertilization in Sweden: a lifetime tax perspective. Scand J Public Health. 2008;36(8):841-849.

34. Kröger GB, Ejzenberg D. The fiscal outcome of artificial conception in Brazil - creating citizens in developing countries. Hum Reprod. 2012;27(1):142-145.

35. Smajdor A. State-funded IVF will make us rich ... or will it? J Med Ethics. 2007;33(8):468-469.
36. Akefeldt SO, Finnström O, Gavhed D, Henter JI. Langerhans cell histiocytosis in children born 1982-2005 after in vitro fertilization. Acta Paediatr. 2012;101(11):1151-1155.

37. Stewart LM, Holman CD, Hart R, Bulsara MK, Preen DB, Finn JC. In vitro fertilization and breast cancer: is there cause for concern? Fertil Steril. 2012;98(2):334-340.

38. Simonstein F. IVF policies with emphasis on Israeli practices. Health Policy. 2010;97(2-3):202-208.

39. Drummond M, Barbieri M, Cook J, et al. Transferability of economic evaluations across jurisdictions: ISPOR Good Research Practices Task Force report. Value Health. 2009;12(4):409-418.

\section{Publish your work in this journal}

ClinicoEconomics \& Outcomes Research is an international, peerreviewed open-access journal focusing on Health Technology Assessment, Pharmacoeconomics and Outcomes Research in the areas of diagnosis, medical devices, and clinical, surgical and pharmacological intervention. The economic impact of health policy and health systems organization also constitute important areas of coverage. The manuscript management system is completely online and includes a very quick and fair peer-review system, which is all easy to use. Visit http://www.dovepress.com/testimonials.php to read real quotes from published authors.

Submit your manuscript here: http://www.dovepress.com/clinicoeconomics-and-outcomes-research-journal 